\title{
Corporate Ethnography and Clinical Research: Thinking a Case Study of Software Evaluation
}

\author{
Pedro Oliveira \\ Independent Consultant \\ Global Associate at Practica LLC
}

\begin{abstract}
Anthropology in business is currently going through a huge expansion in the intersection between thinking and academia. The time is apposite to revisit the relation between theory and practice in anthropology. Drawing from ideas in applied anthropology, design research, and organizational studies, I suggest that the intersection between ethnography and a clinical research approach can help refine the relation between theory and practice in design and business anthropologies. Furthermore, I bring in the idea of formulation as used by clinical psychologists and propose an idea of anthropological formulation, blending ethnography and a clinical research process. A case study on the ethnographic assessment of software is used as an illustration.
\end{abstract}

\section{INTRODUCING THE JUNCTIONS}

At present times, intersections between anthropology and business seem to be growing exponentially. According to Marietta Baba, in the USA, anthropologists and corporations have been mutually involved since the 1930s (Baba, 2006; 2012). The rise of publications in the field of anthropology in business over the last two decades signals a change of direction whereas, at least as matters of corporations are concerned, practice seems to be acquiring a greater role in shaping the conversation in academia. Alongside these developments there are now two academic journals dedicated to business anthropology matters, the Journal of Business Anthropology, published by Copenhagen Business School and the International Journal of Business Anthropology, published by Sun-Yat-Sen University and North American Business Press. These developments happen alongside an international conference focused on ethnographic practitioners, now in its tenth edition (EPIC), and a growing academic interest in the work of scholars and scholar-practitioners in the area.

To date, the most complete expression of the rise of business and design anthropology matters is embodied by the Handbook of Anthropology in Business (Denny \& Sunderland, 2014), a monumental collaboration of over sixty scholar-practitioners situated in universities and corporate settings. That the Handbook of Anthropology in Business is edited by two people situated in practice (both Rita Denny and Patricia Sunderland are private researchers in a consultancy firm) should itself constitute proof of a power rebalancing between practice and academia, where the former is no longer the end recipient of ideas stemming from the latter, but one term of a mutually implied double-destination.

History and contemporary enthusiasm do not always see eye to eye. As Marietta Baba has suggested, the mutual generative influence played between practice and academia has been the case for a very long time, most likely since the beginning of anthropology as a discipline. Present times tend to introduce as 
novelty what historical analysis discloses to be repetition: it is only the lack of familiarity with the work of applied anthropologists by anthropologists situated in academia that gives the appearance of a lesser interconnection between the two domains at the foundation of the discipline (Baba, 1998). If this is true of the American context, it is twice as true of the European context where due to historical reasons connected to colonial legacy, matters of applied anthropology have traditionally faced a slower development (Baba \& Hill, 2006).

As a private consultant working in matters of anthropology in business and associated areas, this article follows the lead of consultants and scholar-practitioners like Patricia Sunderland and Rita Denny (Sunderland \& Denny, 2007; Denny \& Sunderland, 2014), Timothy Malefyt and Robert Morais (Malefyt \& Morais, 2012), MaryannMcCabe (e.g. McCabe \& Malefyt, 2013; McCabe \& Fabri, 2012), Genevieve Bell (Dourish \& Bell, 2011), Melissa Cefkin (Cefkin, 2009)Brigitte Jordan (Jordan, 2013), Sam Ladner(Ladner, 2014), Robert Tian (Tian\& Lillis \&Van Marrewijk, 2010) some of them contributors of the Handbook of Business Anthropology, who, whether situated in practice or occupying intermediate positions between practice and academia, are united by an effort to carry on contributing to theoretical developments in anthropology.

Psychology, in comparison with anthropology, is a field where applied developments of all kinds abound, organizational and clinical psychologies among the examples. It is my contention, as well as the contention of others in the field (e.g. Morais \& Malefyt, 2010), that corporate anthropology must establish a conversation with psychology, if only due to its greater popularity in the language of business. Taking the lead from Edgar Shein, an organizational psychologist who has fed on ideas of clinical research and intervention as a drive for applied organizational work (Shein, 1993), I will extend his original preposition and suggest the possibility of importing an idea of 'formulation', as present in the work of clinical psychologists (Johnstone \& Dallos, 2006) into anthropology in business. Moreover, I will suggest that 'formulation' is an idea already present in the writings of applied anthropologists in deep connection with what we have come to address as a feedback theory of practice in applied anthropology (Baba, 1998), or with what is understood as the "clinical level" in design research (Friedman, 2003). This article does not incorporate Gibert Heardt's conceptions of "clinical ethnography" (e.g. Heardt, 1990) for many reasons, one of them being that clinical ethnography, enmeshed with the psychoanalysis of sexual development, is essentially an effort of explanation of the human condition, rather than an attempt of applying anthropology to organizational change.

Last but not least, drawing from my own practice as an applied anthropologist working for corporations, I will give an example of a corporate case in the technology sector, exploring the process of field note taking and the construction of a relation with my co-researcher in the field (a designer) as the main elements which inform the formulation of this particular case. Situated in corporate anthropology, I dare remark that "formulation" and a "feedback theory of practice" are ideas that could be revisited in others fields within applied anthropology in order to promote associated theoretical advances.

\section{THINKING AT THE JUNCTIONS}

According to Ken Friedman, most definitions of design share three attributes. The word design "refers to a process"; this process is "goal-oriented"; it is a process that works towards "solving problems, meeting needs, improving situations or creating something new and useful" (Friedman, 2003: 508). Anthropology in design, as it relates to business-oriented processes, shares this formulation. From the moment of the first conversations with the client, to the fieldwork process per se, to particular prototyping and co-design activities taking place along the fieldwork (Darrouzet \& Wild \&Wilkinson, 2009), or as the stage following fieldwork, anthropology in design is predominantly a goal-oriented process (Gunn \& Otto \& Smith, 2013). Moreover, its goals are not set in stone from the beginning of a process, but are part of an ongoing negotiation with what Jordan and Lambert call our "corporate counterparts" who tend to speak, at the beginning of a process, in terms of specific goals even when it is the case "that at least in the beginning what they really need from us is less than clear" (Jordan \& Lambert, 2009: 99). In a sense, the refinement of goals happening along the process is in itself part of the anthropologists' intervention. Such 
a process of recursively negotiating meaning with a client seems to feed on what Ken Friedman calls the 'clinical level' of design research:

"The nature of design as an integrative discipline places it at the intersection of several large fields. In one dimension, design is a field of thinking and pure research. In another, it is a field of practice and applied research. When applications are used to solve specific problems in a specific setting, it is a field of clinical research" (Friedman, 2003: 508)

Such a definition coincides, in a way, with what Marietta Baba suggests as a "feedback theory of practice" in applied anthropology. Examining the literature of applied anthropology, the author identifies four types of theories of practice in applied anthropology, each connecting theory and practice in a given way.

In the first theory of practice ('theoria'), theory must precede practice and the value of an application becomes intimately correlated to the theory that makes that practice possible. Theoria postulates a unidirectional relation between practice and theory by which an application's value is determined by the theory at its origin. Another relational pattern of theory and practice within applied anthropology concerns policy. Here, the relevant question is whether applied work informs decisions of measurable outcomes which are argued to improve the human condition. A fourth theory of practice ('praxis') emerges connected with Marxist theory and establishes that in an attempt to change the world through our actions, we come to recognize it.

In Baba's taxonomy, another theory of practice is also concerned with matters of representing and intervening, not arising from a particular political ideology, and relates to applied anthropologists who have made developments in the field of applied clinical anthropology such as A. M. Foster. The proximity between this model and the medical fields is so high that it leads Marietta Baba to argue for the existence of a clinical method in strict connection to A.M. Foster's work (Baba, 1998:25).

Unlike theoria, a feedback theory of practice encompasses the possibility that practice can send signals back to theory. According to this position, practitioners should be trained to manipulate the same ideas as theorists and their intellectual work is just as capable of provoking theoretical developments. Tracing a correspondence with theory building in design research, a feedback theory of practice in applied anthropology would correspond to a middle level between pure research (or basic research, in Friedman's terms) and its applied expression, devoted to adapting the findings to classes of problems (Friedman, 2003: 508). As Friedman himself adds, clinical research involves the exercise of making use of the findings of basic and applied research to specific situations (Friedman, 2003:508). Thus, the work of the applied anthropologist trying to solve a problem in a particular case, in response to a client's request for help - as in assessing software ethnographically in the example given in this article-would be the equivalent of what Friedman designates as the clinical level of design research.

In what feels like a strong convergence with Friedman's field of organizational behavior, Edward Shein has suggested the importance of a clinical research perspective in organizational work:

"Clinical Research should not be confused with qualitative research or ethnographic research (...). What is broadly labeled "qualitative" or "ethnographic" or "participant observer-based" research still operates from the traditional scientific model in which the investigator at his or her own initiative requests entry or infiltrates the research site and makes observations without disturbing the situation (...). The essence of clinical research is that someone in the organization has requested some form of help and that the researcher comes into the situation in response to the needs of the client, not his or her own needs to gather data(1993: 703)".

Hence, Edgar Shein's definition of clinical research in applied organizational work fits with Ken Friedman's definition of the clinical level in design research. Both are concerned with practical action and responding to its challenges; both give away with the idea of a researcher whose prime aim is not to disturb the field, concerned with gathering data for their own purposes, and replace it with the image of a research-practitioner (or practitioner-researcher, considering the everyday activities of a designer at work) gathering data in the act of trying to change something, while learning in the process of inducing change. 
None of them, however, departs from a particular ideological or political stance in their definitions of clinical research. Unlike praxis in Marietta Baba's taxonomy, in both cases, clinical research does not seem to emerge as an attempt at ideologically informed change. This places an idea of clinical research in the intersection of these three fields as being closer to what Marietta Baba addresses as a feedback theory of practice than Marxist-informed praxis. Thus, the work of the applied anthropologist trying to solve a problem in a particular case, in response to a client's request for help (as in assessing software ethnographically in the example given in this article) would be the equivalent of what Friedman designates as the clinical level of design research. This is also the case of what is called clinical research in the practice of clinical psychology, where a constant feedback between practice and theory, under an idea of formulation, guides the clinician's work.

In clinical psychology, a formulation "is the tool used by clinicians to relate theory to practice"; formulations can best be understood as "hypotheses to be tested" (Butler 1998:2, 4 via Johnstone \& Dallos, 2006:4). Formulations presuppose a particular relation with theory that is somehow portrayed as different in anthropology. Anthropological beliefs in the process of ethnography, as hitherto conveyed in ethnographic teaching manuals, tend to portray theory as the kind of pre-conception which needs to be put aside in order to free the anthropologist's mind towards the experience of the fields (e.g. Campbell \& Lassiter, 2014). Such claims likely correspond best to a particular mythology of differentiation of anthropology set against other disciplines rather than the way the anthropological process actually unfolds, although to prove this would require an extensive examination or work in industry and beyond it. Clinical psychologists, in their turn, are less shy in declaring that in spite of the need to push away one's preconceptions in order to get to know a particular patient, there are specific theory-fuelled positions held by the psychologist which are present from the outset, acting as filters towards the information gathered. Producing a hypothesis about a client in clinical psychology (formulating a given case) occurs through the explicit use of theoretical models, sometimes antithetical. Formulating as a practice is also consistent with Shein's definition of clinical research in applied organizational work as a process in which " (a) the client wants help and is therefore more likely to reveal important data and (b) the clinician researcher is expected to intervene, which allows new data about the client system to surface" (Schein, 1993:705) ${ }^{3}$. It is equally consistent with the position of the anthropologist working in industry in that this too is a process where a client emits a request for help, formulating and revising goals with the anthropologist as they go along, and expecting them to either suggest a kind of intervention or to produce the recommendations which can frame an intervention.

Like the idea of formulation in psychology, anthropologists in industry often declare particular theoretical positions from the outset. For instance, Patricia Sunderland and Rita Denny have written extensively on the use of semiotics as a tool for doing anthropology in consumer research; semiotics as means of understanding culture and the market are both part of their thinking and the presentation of the company where their work occurs, Practica LLC (e.g. Sunderland \& Denny, 2007). Grant McCracken, someone who dwells both on the realms of teaching and private consultancy, equally professes a semiotic penchant for the understanding of culture in the practice of marketing and anthropology (McCracken, 1990; 2005). Work in anthropology and technological corporations, from Lucy Suchman at Parc-Xerox (Suchman, 2007) to contemporaries such as Paul Dourish (e.g. Dourish, 2004), does not exclude semiotics but it has carried the distinctive influence of ethnomethodology. Unlike the myth of the freetheory anthropologist facing a new field, often conveyed by teaching manuals in anthropology, semiotics and ethnomethodology are not coincidental findings of the data of different researchers working on similar problems that happen to arrive at similar theoretical choices as a matter of serendipity in a field with no preconceptions to start with. Rather, these distinct theories are observational and experiential keys present from the outset, shaping the nature of the participant-observation occurring in the field and sometimes part of the anthropologist's strategies of self-presentation.

In what is a classic of formulation theory in clinical psychology, Lucy Johnstone and Rudi Dallosrevisit the same data regarding a patient five times under five different theoretical models: a cognitivebehavioral interpretation, a psychodynamic interpretation, a systemic interpretation and what the authors address as a social constructionist and a social inequalities formulation-two categories that in an 
anthropologists' formulation would likely be grouped together (Johnstone \& Dallos, 2006). The idea of thinking aloud the same anthropological material, sometimes as a means of questioning the anthropologists' authority is by no means new to anthropology; a classic example of it is Margery Wolf's "A Thrice Told Tale" (Wolf, 1992). However, Wolf"s triple re-description does not work by reinterpreting the same data three different times in the light of three different theories in anthropology. In some respects, anthropology and psychology share similar theories. There is no reason why the same ethnographic event or story could not be re-interpreted in the light of cognitive anthropology, psychoanalytical anthropology, systems anthropology, or a social construction interpretative frame, amongst other possibilities. To do so, however, would easily contradict the mythology of the anthropologist who must learn to renounce theoretical pre-conceptions to truly start their fieldwork.

In design research theory, the idea of theory being present from the start is here explicit, as it is in psychology "(...) scientific knowledge arises from the theories that allow us to question and learn from the world around us" (Friedman, 2003:521). The assumption that lower levels of theory can equally send signals back to fundamental theory is also explicit in design research, with Friedman stating that applied research "adapts the findings of basic research to classes of problems" but also that "applied research may develop or generate questions that become the subject of basic research" (ibid: 508). What is perhaps left unsaid in Friedman's reflection, bearing his "clinical level of research" in mind, and more obvious in the work of Edgar Schein, is how the relation between client and researcher can be extended as an analogy of a clinical relation. For instance, in a given case of anthropology in industry, what defines the form of collaboration between client and ethnographer? What constitutes reflective practice by the researcher in a client-ethnographer relation? What goes in a particular description of the client and its problems? What kind of elements of context feed that description? Can you relate the description to one or more particular theories in anthropology? Can you integrate different theoretical models into the description? What makes this description true? And ultimately, why do we need it?

These are some of the questions that are equally valid for work with clients, both in clinical and organizational settings. By reporting an ethnographic case in which I was involved, I will explore some of these questions while trying to illustrate how a formulation unravels in the small, daily acts of ethnographic work.

\section{RESEARCHING AT THE JUNCTIONS}

The client is a technology firm\& software provider and I have been contacted to research a particular work application produced by this firm. For the sake of confidentiality, I call this application TASK. TASK is used in several sectors, from banking, to technology to telecommunications. Our client's client is a private organization in the technology sector where different teams have been using TASK for many years now. For the sake of anonymity, I will call our client's client VARIED.

Our job is to go to VARIED and assess TASK at work, that is, sitting with our client's client over the course of two weeks and seeing how different teams within VARIED make use of the software. Soon into my first day, I am introduced to the person who is going to be my partner in the field, a designer who has never conducted any form of ethnographic research before. For the sake of confidentiality I will call her Diana.

My first contact with Diana is partially about relieving her anxiety in this matter while making her feel safe enough to toy with the idea of doing research side-by-side with an anthropologist. In other words: it is about building trust. In time, Diana will prove a very astute observer, making use of the kind of visual memory and visual mapping more often the property of designers than of text-based anthropologists. Diana is capable of reproducing in her mind what feels to me highly detailed screen sequences as they unfold in the computers that we observe at VARIED, before converting them into notes.

VARIED is a big organization. The first days are about selecting what teams we are going to interview and to sit next to, in the process of conducting fieldwork and defining our access to the field. We arrange things with TASK's product owner (the person based at our client's client who is in charge of 
this software) and let the teams be selected between him and my direct client. Hence the first moments in the field are about defining various forms of collaboration: collaboration between Diana and myself on what kind of research we are going to do together, what our goals will be, our schedules, and our methods. I will explain to Diana some details on fieldwork and fieldnote taking before joining the field: collaboration between our client, their client, and the product owner regarding which teams will be selected for this study and consequent system definition; my own mental retrieving in case studies of ethnography at work and of ethnomethodology, which does not happen by chance, but because ethnomethodology is the theoretical school most feeding into anthropological studies of technology at work; the mapping of power and hierarchical relations in my client and their client, sitting side-by-side with the mundane details of planning our research schedule together with Diana and the teams selected.

In this case, the prime strategy involves interviewing the managers in each team, before we negotiate sitting next to the teams while watching them using the software in their everyday routines. This will be followed by debriefing sessions between Diana and me, when we will compare our understandings and notes on the field at the end of each day. All of this contributes to a first sketch of a hypothesis on what is going on: in other words, an initial "formulation". At the moment, my hypothesis is a need to find out if TASK is mirroring a particular relation between my client, client's client and product owner.

As an anthropologist (the 'exotic other', in a technology context) has been called to the case, the chances are that TASK is mirroring a relation in need of help. Our priority is now finding out what kind of data needs to be identified for that help to be provided and how to best represent it in order to clarify communication between my client, the client's client and the product manager. It is defined at the beginning of the project that my final deliverable will be molded in terms of personas and scenarios. Personas are representations of stereotypical consumers, their saying, habits and practices. Scenarios are typical patterns of interaction in which these personas move.

Making my presence in the field less exotic involves building a common rationale with the client and namely with the co-researcher. Brief explanations of what anthropologists do in a corporate context and how they go about taking notes are shared with my co-researcher in order to build a more or less common understanding of how we will make our learning process at VARIED understandable to each other. As fieldwork progresses and information starts being fed to the client, the challenge becomes how to share and build a common rationale with my client. This rationale will likely be used in the future, as a bridge for talking about TASK difficulties and potentialities.

The first days in the field are about making sense of the different teams using TASK, their functions and what differentiates these teams from one another. With two weeks as the deadline for our ethnography, this is an exercise that we will carry on right to the very end of fieldwork. When interviewed about TASK, we receive plenty of information, a substantial amount of it not directly related to the application itself, but to organizational changes inside this corporation that are contributing to an increase in work frustration. This is something, in part, conveyed in the use of TASK.

When sitting next to research participants (as opposed to interviewing them in a formal setting) we tend to note what other applications people are using to complete their daily chores. As usual in ethnography, it is in the act of thinking aloud in the presence of a researcher or letting oneself be observed in the process of completing a task, rather than talking through an interview script in a distant room, that the richest information comes to light.

Another aspect that we become very attuned to is what kind of aids people are using to circumvent difficulties related to the use of TASK. After a few days we find that there is a spectrum of commonly used aids to work through the contextual difficulties posed by task, going from interpersonal aids to paper aids. Paper aids may be notes of operations not completed on TASK, needing completion within a set deadline. Here, the participant takes a note on a piece of paper as a memory aid to oneself. Other kinds of aids involve a negotiation with others. For instance, letting your work partner know, in person, via email or chat, that you are about to complete an operation on TASK with a strict deadline associated to it and involving work on their side as well.

Being in the field, chasing TASK across the building and its various teams, regurgitates the differences between anthropology, genealogy and history. In enquiring who are the originators of TASK 
we come across a multitude of stories that in a final analysis, contradict each other. As with all genealogies the contradictions are not expressions of tension and conflict as it happened in the past as much as expressions of tension and conflict happening in the present (tensions around the current uses of TASK symbolized in different myths regarding its origin). Surprisingly for me, there is an emotional relation with the software evident in people's ways of reminiscing about it. Employees who have worked with it for a really long time, when talking of TASK, talk about a time when they were younger, when the company was younger too, and of a sense of community in those days which is no longer found in TASK and beyond it. As days unfold, talking software becomes many things, and certainly a way of talking about institutional life.

Across teams we also find out that people have been devising their own pedagogical guides for using TASK and passing the information to neophytes. We collect as much of this information as we can. As in a clinical relation, another task that we understand we are being put onto is to somehow relieve part of the product owner's stress facing distinct teams making different requests around TASK, often incompatible ones.

In the interactions with people of VARIED the influence of ethnomethodology is there all along, or even, thinking via Paul Dourish, "technomethodology" (Dourish, 2004). This is expressed in many ways. Its first expression concerns mapping how actors are working to maintain an idea of stability of the social world they help to constitute (Garfinkel, 1984). Thus, we are trying to see how different actors contribute to make TASK stable and the social world associated with it stable, through the different interpersonal aids that are not found inside the software, but in human, everyday life encounters. "Keeping a stable world" starts feeding and shaping the formulation. At this point, as Friedman would likely put it, problems of basic research (ethnomethodology theory) and applied research (cases in work technology dealt from an ethnomethodology viewpoint) become clinical research (carving the relation between TASK and ethnomethodology).

We sit with informants in order to map their actions towards TASK while trying to capture these actions as flows of 'naturally occurring, improvisational response to practical problems' (Dourish, 2004: 77). In the language of design, Diana, my co-researcher, will call them 'sequence diagrams'. We look at accountability, another major theme in the ethnomethodology tradition, as a set of practices in observing and reporting data put forward by members of VARIED within and across teams. Inversely, we look for stories where people have not made enough effort to remain intelligible to others inside TASK so as to understand what accountability means from the people's point of view. And in good anthropological fashion, we occasionally have lunch with the research participants, trying to get a sense of what their daily life is about, beyond TASK talk and observing.

We look at dependence and how TASK creates inter-dependence across teams. As in plenty of organizational software, there are a vast number of operations that can only be completed through cooperation of members of different teams distributed across a variety of hierarchical levels. The interdependence of other teams often works as a source of frustration inasmuch as what is completed in TASK is quantified and quantifiable. Hence, delay by a member located in another team implies delay for oneself and subsequently for one's team goals. Here, the formulation moves from stability of the social world to what makes stability harder to sustain: hierarchy, power and functional inter-dependence.

An aspect that becomes particularly important during the research is the aspects of other applications used at work which people would like to see 'migrating' to TASK. When invited to think aloud through chores being completed as the researcher sits in, research participants will sometimes take their smart phones out and show us other applications that they are using concomitantly, explaining why the work they do would be much easier if those aspects present in their personal technologies or in other applications, could become a part of TASK.

Spending time doing participant-observation with different elements of the same team, TASK allows one to look for individual styles in using TASK. These individual styles are often translated into idiosyncratic sequences expressed in different sequences for completing the same operation. In this frame, different users will argue their way of doing things as the quickest and most effective. As we map these differences, the formulation moves from a systemic mapping of TASK in relation to other applications 
and functional interdependence across teams to mapping cognitive process in its uses. Elements of systems anthropology and cognitive anthropology are gradually enmeshed with the ethnomethodology starting point.

Across teams, we also try to list adoption barriers. While part of TASK's function is to discourage the use of most operations via email, there are individuals and sometimes groups who persevere in the use of email. Listing the reasons provided by elements of the team as to why this occurs becomes part of our two-week plan.

Within the diversity of teams using TASK, some have made adaptations agreed with the product owner. Adaptations found in the field give us information about particular kinds of needs, which in a final analysis we will call "customization needs". Identifying types of needs under a human-centered design perspective (e.g. Norman, 1998) and displaying them on a pie chart will be part of our final deliverable.

Aggravated by the difficult times we are living in, a sense of organizational frustration, found everywhere to different degrees, sometimes makes TASK its particular expression. Separating what is contextual stress and what in the software is less related to contextual stress, sometimes involves a patient listening through several kinds of complaints. In part, taking from Edgar Shein's viewpoint, this unraveling happens because we are perceived in the field as people trying to map the way for a change, rather than researchers-in-context working solely for our own self-centered purposes. As Johnstone and Dallos (2006: 5) remind us, by quoting Meyer and Turkat 1979: 261), on the notion of formulations in clinical psychology:

"A formulation...1. relates all the client's complaints to one another, 2. explains why the individual developed these difficulties, and 3. provides predictions concerning the client's behavior given any stimulus (Meyer and Turkat 1979: 261)".

Coincidentally or not, by our last days in the field, my design colleague, to whom the work of psychologists is more familiar than the work of anthropologists, will make a comparison between our work and the work of a therapist listening to their patients. According to Diana, listening to patients is similar to what we have been doing over the past two weeks, except that we have been listening to potential problems related to TASK rather than the kind of problems you would share in a therapists' office. Ironically, this seems to consolidate the product owner's view that the different teams need psychologists more than they need changes in TASK.

Side by side with the rational aspects connected to TASK, our work also becomes about emotional mapping of the application. We come to see that workers who have been in this company for a long time say that internal processes did not use to be framed as much in terms of individual accountability as they are now. To put it otherwise, when they first started working with TASK, the obsession with accountability and subsequent uses of the application to determine accountability were not as present. Some of them will also add that more than a culture of individual accountability, the company seems to have changed into a culture of individual "culpability", a change attributed to external, Anglo-Saxon organizational culture, now migrating to the South of Europe.

TASK, not necessarily in its origins, but in the way it has become used, mirrors this larger cultural change. This pattern is not alien to people conducting applied ethnography on organizations and information systems; for instance, in the field of health, Don Norman (Norman, 2010) reports health professionals who claim to spend so much time filling in forms designed for the quantification of their activitiesthat they subsequently have little time for actual physical contact. At VARIED, a similar complaint seems to emerge from workers regarding the time spent dealing with forms suitable to quantification and the time spent dealing with activities that will truly benefit the end user.

Needless to say, despite the analogies between therapeutic work and design ethnography work conducted around TASK, we are not dealing with the psychopathology of an individual, a family or a therapeutic group. We are dealing with a corporate organization, like so many, currently experiencing the hardship of an economic recession. If, in the kind of formulation often put forward by North American design and business anthropologists, what we are talking about when talking about TASK is a form of 
organizational "culture", perhaps it is worth narrowing down what kind of meaning goes into that culture. Another way of putting it is to respond to Diana's perplexity: if what we are doing is almost like a form of therapeutic listening, what unifying ideas allow us to debrief on what we are constructing as a shared reality? And inversely, can that shared reality have an effect on the meaning going into 'culture'?

My involvement with TASK and VARIED finishes off with a final presentation to my client; as a final deliverable, Diana and I include a detailed needs map, a list of behaviors of cooperation around TASK and a shorter section around emotional aspects. The final deliverable, presented in a videoconference involving about ten members of the company, gives rise to a heated debate around the past, present and future of this application. In what were emergent concerns about its present uses, the history of the applicationand subsequently the many versions of those who were involved in that past, were surprisingly brought into the discussion, amongst various other aspects. Not unlike post-modern therapy, TASK was invited to a narrative re-inscription of itself. At this point, the formulation reaches a new stage: how to account systemically for the triad constituted by ourselves, the client and our client's client. It is perhaps no coincidence that as this relational triad becomes clearer in its overt and latent goals, the consultancy work, as agreed initially, reaches its conclusion.

\section{CONCLUSION: TREATING THE JUNCTIONS}

Recent work on design anthropology (e.g. Clarke, 2011; Gunn \& Otto \& Smith, 2013) seems less concerned with psychological anthropology and/or intersections of anthropology and psychology than other areas within academic anthropology. As suggested by Morais and Malefyt (2010) in the exercise of mediating across multiples worlds of inquiry (such as the world of TASK, VARIED and my client), one should acknowledge that psychology is very much an integrating part of the world of business; doing anthropologically-informed business ethnography, whether or not with a focus on design, can only ignore the relation between psychology and anthropology at its own peril.

North-American business anthropologists tend to be more culturally orientated than their 'social relations' peers, a difference in training shaping those either side of the pond. In the work of American peers, an idea of culture is often evoked to account for an explanation of organizational behavior. In this article, I advance a slightly different suggestion: one that brings business and design anthropology closer to clinical psychology than organizational studies, while not rejecting a notion of culture; and one that seeks an idea of formulation brought into matters of design anthropology without making it 'clinical' in the medical sense of the term. If trouble-shooting is often what we do, then a notion of formulation as a link between theory, problem identification, research participants' behavior and recommendations, is one that may suit us just as well.

That ethnomethodology happens to be the starting point at the basis of my formulation is no coincidence insofar as ethnographic studies on work software have carried a distinct ethnomethodology influence. As the formulation evolves in the field, however, the influence of different theories starts building into it. The formulation becomes integrative. Throughout, the formulation builds relationally in the multiple triads formed by the ethnographer, one's co-workers, research participants and client. Attending to these multiple relations is attending to how a system is formed in the field situation itself and attending to the impact that this will have on understanding the application in the social world it helps to generate.

As Roy Wagner would remind us, culture is many things, an act of invention being one of them. When people create strategies of cooperation and solidarity around a given software, TASK or other, they are not likely expressing psychopathology around the software as much as finding their own creative ways of holding to a form of stability in the social world that requires creative cooperation by all of the people involved. Inversely, it is this cooperation that sustains the experience of a social world, with its absence being lived as a fear of danger and dissolution.

Against this background of creativity over pathology, to speak of a clinical form of research operating all along may sound like a contradiction in terms. Yet, bringing together Ken Friedman's sense of the clinical level of design research and Edgar Shein's sense of learning in the process of trying to create a 
change is perhaps not substantially different from what Marietta Baba's remarks implied is already a part of the history of applied anthropology; this is the possibility that practice can send signals back to theory. What kind of signals is TASK sending back to theory?

Perhaps out of the many signs that TASK is sending back to theory, there is one in particular worth bearing in mind: that we should start practicing, thinking and writing about design and business anthropologies through the eyes of a feedback theory of practice breaking disciplinary divisions between anthropology and psychology. That, which this article tries to be an example of, would likely allow us to become more effective at treating junctions between practice and theory in a world of emergency begging for peace between them.

\section{REFERENCES}

Baba, M. (1998). Theories of Practice in Anthropology: A Critical Appraisal. In: The Unity of Theory and Practice in Anthropology: Rebuilding a Fractured Synthesis. Carole Hill and Marietta Baba, eds. Washington, DC: National Association for the Practice of Anthropology, pages 17-44.

Baba, M. (2006) Anthropology and Business. Encyclopedia of Anthropology. H. James Birx, Ed. Thousand Oaks, CA: Sage Publications. Pages 83-117.

Baba, M. (2012). Anthropology and Business: Influence and Interests. Journal of Business Anthropology.1(1):20-71.

Baba, M. \& Carole, L.E. Hill (2006) What's in the Name 'Applied Anthropology'? An Encounter with Global Practice. In: The Globalization of Anthropology. NAPA Bulletin \#25. Carole E. Hill and Marietta L. Baba, Eds. Washington, DC: American Anthropological Association, pages 176-207.

Campbell, E. \& Lassiter, L.E. (2014). Doing Ethnography Today: Theories, Methods, Exercises. WileyBlackwell; 1 edition

Cefkin, M. (2009) (ed.) Ethnographyand the CorporateEncounter: Reflections on Research in and of Corporations. Oxford: Berghahn Books.

Clarke, A.J. (2011) (ed.). DesignAnthropology: object culture in the 21st century. Vienna, Springer.

Darrouzet, C., Wild, H., \& Wilkinson, S. 2009. Participatory Ethnography at Work: Practicing in the Puzzle Palaces of a Large, Complex Health Organization. In Cefkin, M. (Ed.) Ethnography and the Corporate Encounter. New York: Berghahn Books.

Denny, R. \& Sunderland, P. (2014). Handbook of Anthropology in Business. Left Coast Press, Walnut Creek, CA.

Dourish, P. \& Bell, G. (2011). Divining a Digital Future: Mess and Mythology in Ubiquitous Computing. Cambridge, MA: MIT Press

Dourish, Paul (2004) Where the action is: The foundations of embodied interaction. Cambridge, MA: MIT Press.

Friedman, K. (2003). Theory construction in design research: criteria, approaches, and methods. Design Studies, 24(6), 507-522

Garfinkel, H. (1984). Studies in Ethnomethodology. Malden MA: Polity Press/Blackwell Publishing.

Gunn, W. \& Otto, T. \& Smith, R. (2013) (eds.). Design Anthropology: Theory and Practice. London, Bloomsbury Academic

Herdt, G. (1999). Clinical ethnography and sexual culture. Annual Review of Sex Research, 10:100-19.

Johnstone, L. \& Dallos, R. (2006). Formulation in Psychology and Psychotherapy: Making Sense of People's Problems. East Sussex: Routledge.

Jordan, B. (2013) (ed.) Advancing Ethnography in Corporate Environments: Challenges and Emerging Opportunities. Walnut Creek, CA: Left Coast Press

Jordan, B. \& Lambert, M. (2009). Working in Corporate Jungles: Reflections on Ethnographic Praxis in Industry. In Cefkin, M. (Ed.) Ethnography and the Corporate Encounter. New York: Berghahn Books.

Ladner, S. (2014). Practical Ethnography: a Guide to Doing Ethnography in the Private Sector. Walnut Creek, CA: Left Coast Press 
Malefyt, T. \& Morais, R.J (2012). Advertising and Anthropology: Ethnographic Practice and Cultural Perspectives. London: Berg.

McCabe, M. \& Fabri, A. (2012). Vitamin Practices and Ideologies of Health and the Body. International Journal of Business Anthropology 3(1) 39-61

McCabe, M. \& Malefyt, T. (2013) Creativity and cooking: Motherhood, agency and social change in everyday life. Journal of Consumer Culture. Online First, June 25, 2013. doi:10.1177/1469540513493202

McCracken, G. (1990). Culture and Consumption: New Approaches to the Symbolic Character of Consumer Goods and Activities (Midland book). Bloomington, IN: Indiana University Press McCracken, G. (2005). Culture and Consumption II: Markets, Meaning and Brand Management. Bloomington, IN: Indiana University Press.

Morais, R. J. \& Malefyt, T. (2010) How Anthropologists Can Succeed in Business: Mediating Multiple Worlds of Inquiry. International Journal of Business Anthropology, Vol. 1, Iss. 1, pp. $45-56$

Norman, D. (1998). The Design of Everyday Things. New York: Basic Books.

Norman, D. (2010). LivingWith Complexity. Cambridge, MIT Press.

Schein, E. H. (1993). Legitimating clinical research in the study of organizational culture. J. Couns. Dev.71, 703-770.

Suchman, L. (2007) Human-Machine Reconfigurations. Cambridge University Press, New York

Sunderland, P. L., \&Denny, R. M. (2007). Doinganthropologyin consumerresearch. Walnut Creek, CA: Left Coast Press

Tian, R. G. \& Lillis, M. P. \& Van Marrewijk, A. H. (2010). General Business Anthropology. Miami, FL: North American Business Press

Wolf, M. (1992). A ThriceToldTale: Feminism, Postmodernism, and Ethnographic Responsibility. Stanford, CA. 